\title{
Isaac Newton Institute for Mathematical Sciences
}

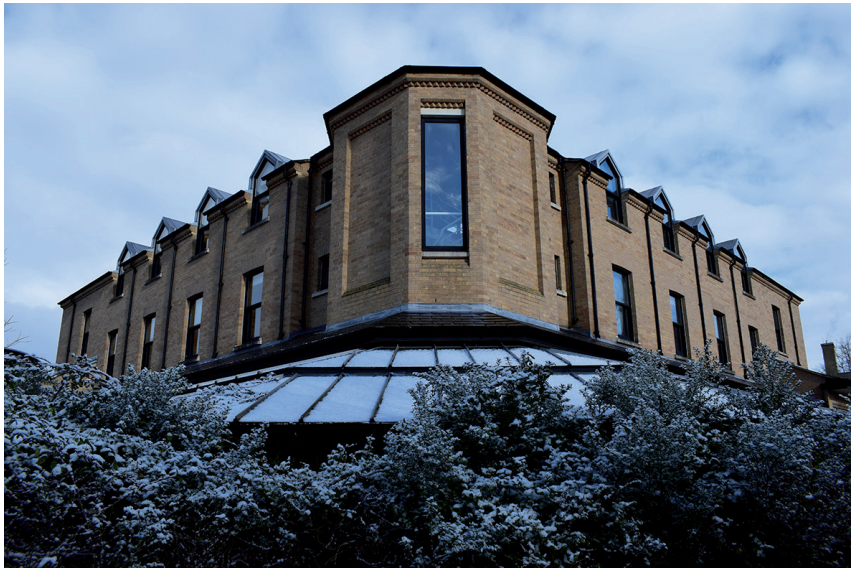

The INI building seen from the south-west.

In July 2017 the Isaac Newton Institute for mathematical sciences celebrated the 25th anniversary of its opening, a quarter of a century that had seen a total of 133 research programmes undertaken within its walls, seminar rooms, offices and collaborative work spaces. That figure is now at 145 . Based on the University of Cambridge's mathematics campus, the Institute is privileged to be a part of one of the world's leading centres for the advancement of the science as a whole - a position in which it continues to thrive.

\section{A place for collaboration}

INI's distinctive architecture characterises it as a collaborative space, embracing both open, shared spaces ideal for group discussion and smaller, more private offices for quieter work in smaller groups. The building is typically occupied by up to 70 mathematical scientists at any one time - with three times that number during workshop weeks. Many of these participants will not have met before and others may not realise the relevance of other research to their own work. Whether early-career researchers or senior academics, or between those two groups, collaborations and networks are routinely formed within this space that last a lifetime. The Institute runs scientific programmes varying in length from four weeks to six months. At any particular time there are typically two or three programmes running in parallel, each with between 20-30 participants working at the Institute. Week-long workshops are run at regular intervals throughout these programmes to allow outside speakers or other researchers to contribute to the programme in shorter, more intense periods of interaction. Selection of these programmes is made by a panel of leading mathematicians. The criteria are that a programme should have great scientific merit and be at the forefront of current

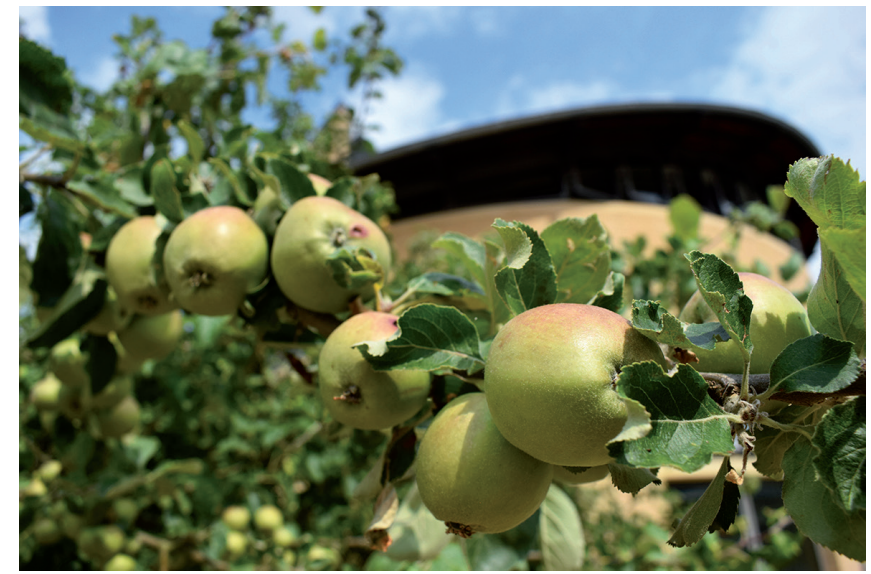

The apple tree in the garden to the rear of the INI building - planted by Lady Atiyah, wife of the first Director of the Institute, as part of the opening ceremony in July 1992 - is said to be a descendent from the tree that inspired Isaac Newton.

developments where a significant scientific breakthrough can be expected, be intra or interdisciplinary by nature, and to have the highest quality leadership and participants. By identifying subjects that have both substantive mathematical significance and clear common ground for collaborative study, the Institute is able to transcend the boundaries of departmental structures.

\section{The Institute in numbers}

Throughout a typical year the Isaac Newton Institute will host over 500 such programme participants and 1,500 workshop participants, amongst which regularly feature winners of the Abel Prize and the Fields Med$\mathrm{al}$, as well as other prestigious awards. Together these groups will account for around 25,000 participant days of activity, allowing for both a broad scope of subjects to be covered and profound, meaningful progress to be made across them. Within the past two years, for example, programme themes have included, but not been limited to, a variety of pure and applied areas such as: symplectic geometry, computer vision, uncertainty quantification, homotopy theory, the mathematics of sea ice phenomena, the design of new materials, energy systems, and (inspired by the work of D'Arcy Thompson) the nature of form and self-organisation in living systems. The geographical spread of these researchers' home institutions is evenly split between the UK, the rest of Europe, and the remainder of the world. This makes INI a truly international centre and inspires the kind of cross-pollination of ideas which has the potential to truly move disciplines. A perhaps more quantifiable outcome can be highlighted by the number of research papers produced within the four-year span of 


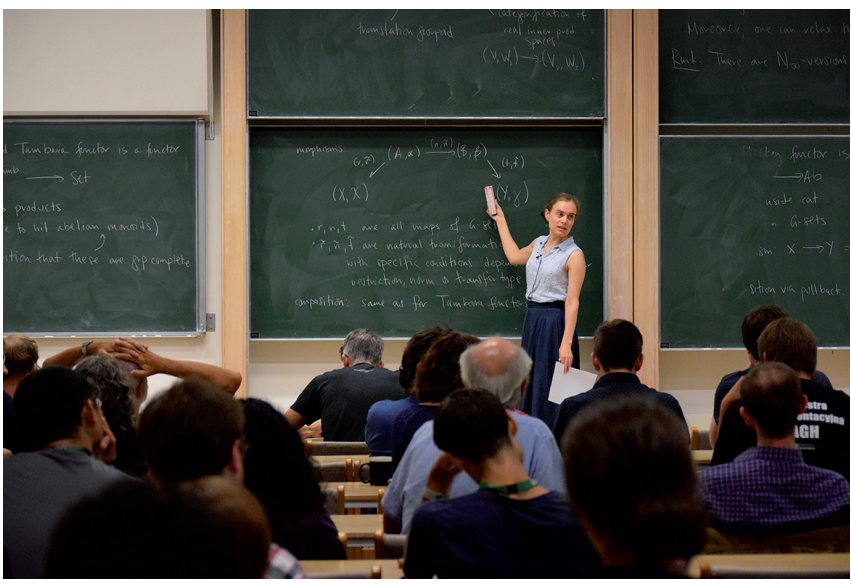

A typical workshop underway in INI's main Seminar Room.

the Institute's most recently completed grant cycle. The number of research papers produced since 2014 stands at around 350, excluding any for which the authors have not acknowledged the Institute.

\section{An increasing output}

A further point worth highlighting is that as the programme frequency at INI has grown in recent years, so has the output detailed above. The decision, taken in 2015 , to regularly increase the number of programmes run in parallel from two to three, has resulted in as many as nine separate programmes occurring within a calendar year. Once the selection of follow-on workshops from past programmes and other one-off events are added to this, the Institute is now achieving within 12 months what it previously may have done across 18 . This growth, of course, necessitates upgrades to the building's infrastructure as well as an augmentation of the administrative structures needed to support such large numbers of visitors. Consequently, in July 2018 work began on the long-anticipated refurbishment of INI's Benians Court properties - themselves just one of the options available for participant housing. This exciting new redevelopment involves the comprehensive update of 24 apartments, all of which are regularly used to house INI visitors and participants. Of those flats, 18 are being altered to contain two double rooms with en-suite facilities, with improved kitchen areas and standardised quality throughout the

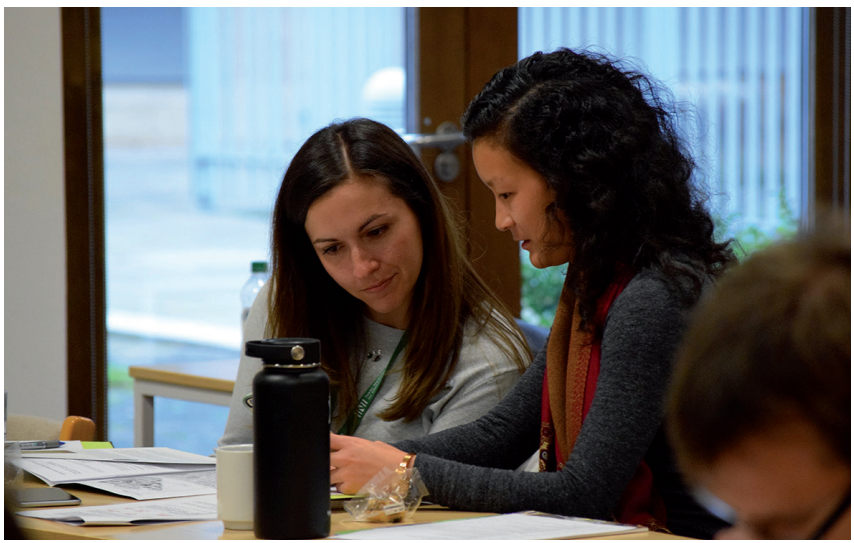

Collaborative working across myriad disciplines lies at the core of INI's philosophy.

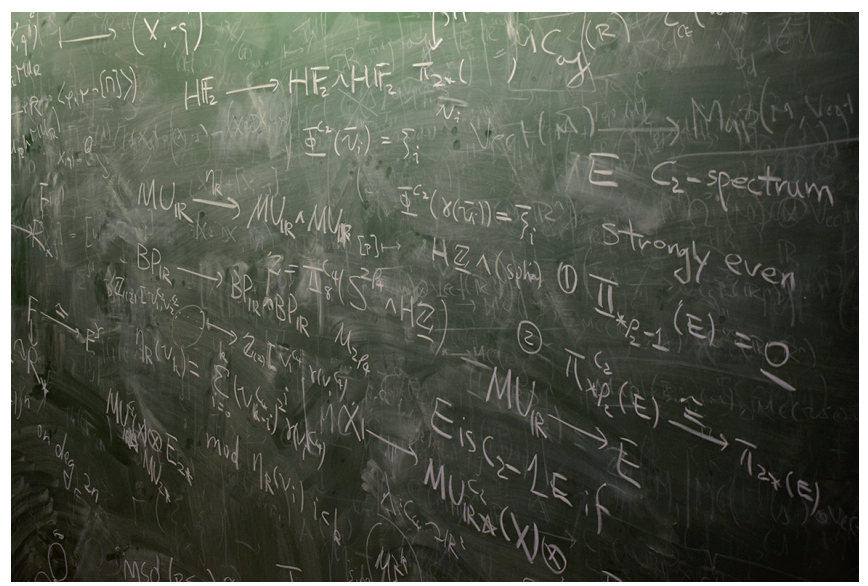

INI boasts over 130 square metres of blackboards.

furnishings. Of the remaining six, two will be fully renovated to ensure complete disabled access whilst four will keep a configuration better suited to housing families. With work on the final phase of the project underway at the time of going to press, work is set to finish on schedule in the summer of this year.

\section{Equality within the science}

As detailed above, throughout its 27 years of operation INI has welcomed pre-eminent mathematicians from across the world - and this has been in part thanks to its Rothschild Visiting Distinguished Fellowship scheme, set up to facilitate the participation of a keynote participant for each programme. In addition, as of 2019, a generous $£ 250,000$ donation from the Turner-Kirk Charitable Trust has allowed the establishment of the new Kirk Distinguished Visiting Fellowship Scheme. This fellowship also provides funding for one senior mathematician per programme; however, these field-leading figures are chosen from under-represented groups within higher mathematical research. As a consequence, they will primarily be senior women mathematicians - as demonstrated by the five scientists so far selected for 2019. It is the Institute's hope that this prestigious fellowship scheme, promoting influential role models within their field, will give confidence and self-belief to early career researchers and hence address the historical gender imbalance that persists within the science.

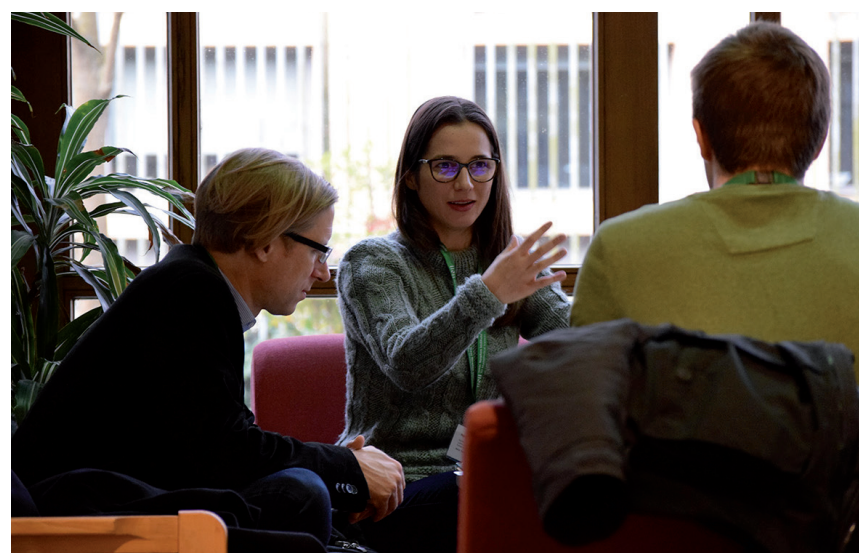

Shared spaces are present throughout the building, making discussions lively and regular. 


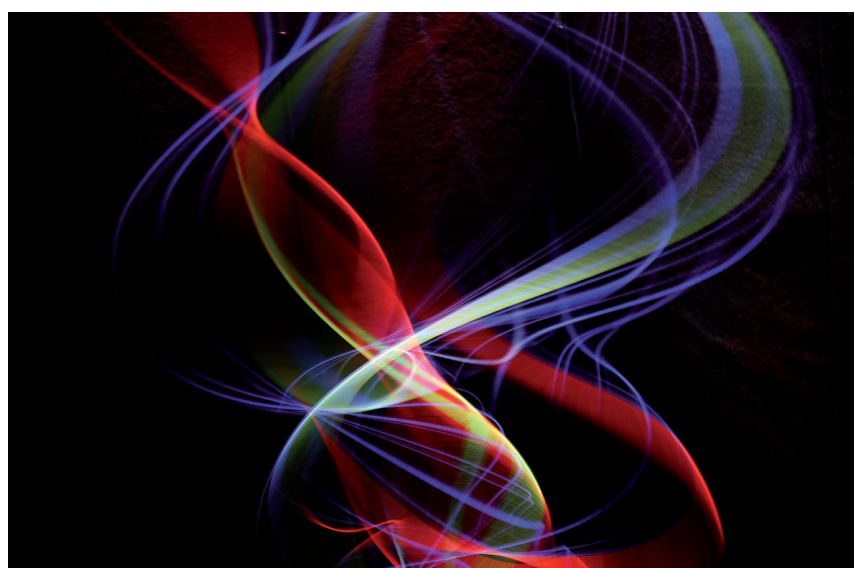

An interactive artwork displayed as part of the "Growth form and self-organisation" programme.

\section{Outreach and public-engagement}

Since 2002 INI has maintained a list of correspondents in UK Universities, other academic institutions and research and development groups in industry and commerce. These individuals act as a channel of communication between the Institute and the mathematical sciences community in the UK. Correspondents are regularly informed about activities of the Institute, and it is their responsibility to ensure that the information is disseminated to the relevant departments in their institution, as well as to provide regular feedback to the Institute. Following a refresh and re-launch in January 2018, which took the number of active members to 84 and established a new Chair to better coordinate the group, the Correspondents Network was branded jointly with the International Centre for Mathematical Sciences (ICMS). This rebranded network launched with the INI-ICMS Correspondents Day meeting in Cambridge on 24 January 2018, and has continued most recently with the 2019 meeting on 30 January 2019 at ICMS' new facilities at The Bayes Centre in central Edinburgh. Within the past two years INI has also taken steps to further its outreach activities and to broaden its communication channels. Examples of this include: hosting the 25th anniversary celebrations of 2017, which welcomed esteemed and popular fig-

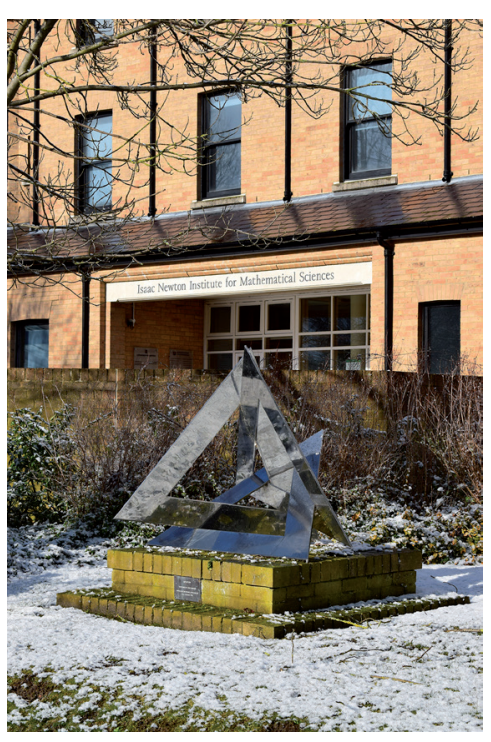
ures ranging from Sir Andrew Wiles and the late Sir Michael Atiyah to Dr Simon Singh and Dr Hannah Fry; contributing to annual popular science events such as New Scientist Live at London's Excel centre and the Cambridge Science Festival (the most recent INI

Three of John Robinson's sculptures mark the entrance to the INI building, all based on the interlocking forms of the Borromean Rings.

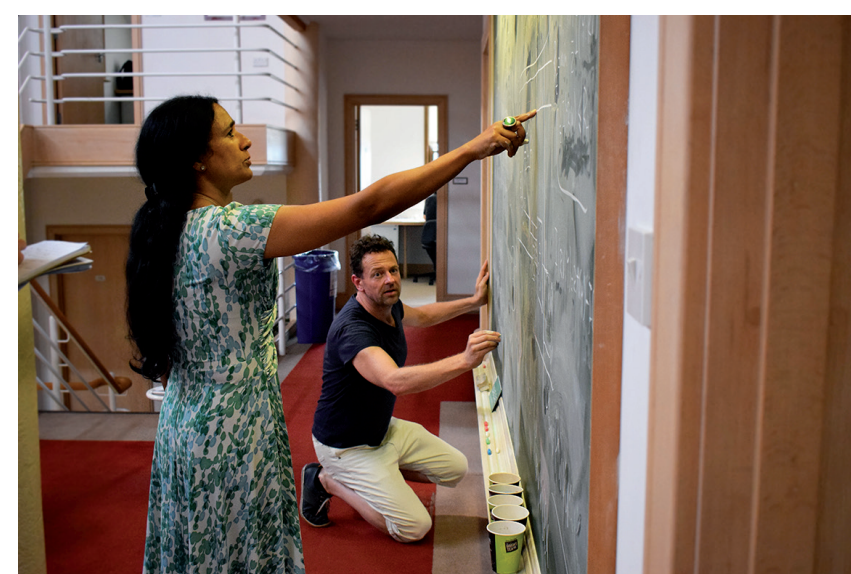

Nilanjana Datta and Andreas Winter of the "Beyond I.I.D. in information theory" follow-on workshop (2018).

speaker being Amazon Alexa's Head of Applied Science Dr Craig Saunders); the publication of a video interview series focused on the programme organisers; the recording of a regular podcast interview series, and more. The Institute is also proud to announce that, as of January 2019, INI's knowledge exchange arm has been renamed the Newton Gateway to Mathematics (formerly known as the Turing Gateway to Mathematics) - a move which clarifies its key role within INI and highlights its essential task of fostering long-lasting relationships between mathematical scientists and other academic disciplines, industry, commerce and the public sector.

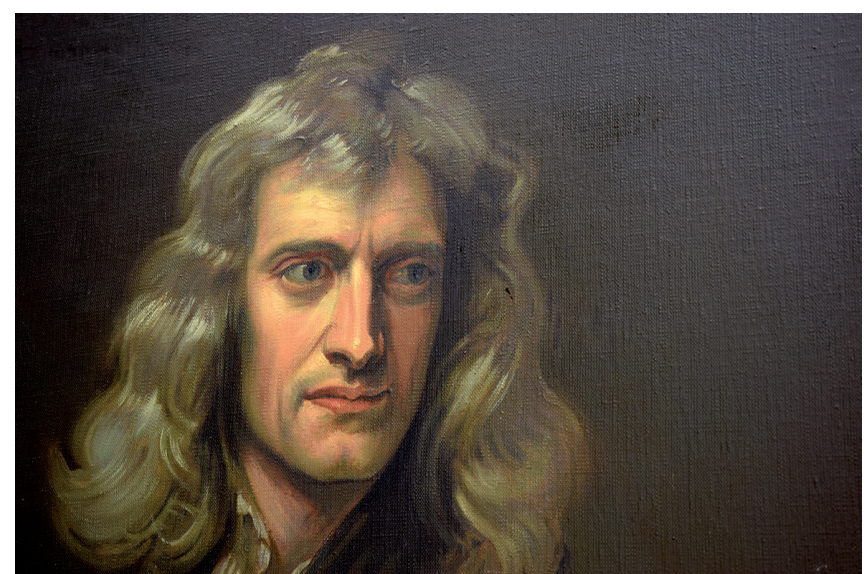

A portrait of Newton displayed at INI. This copy of the original by Sir Godfrey Kneller (1689) was painted by Barrington Bramley and donated to the Institute in 1992.

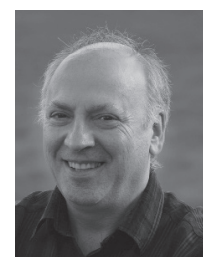

David Abrahams has devoted research effort to the broad area of applied mathematics, and specifically to the theoretical understanding of wave processes, since graduating in 1982 with a PhD in applied mathematics from Imperial College London. Prior to taking up the post of Director of the Isaac Newton Institute, he held the Beyer Chair of Applied Mathematics at the University of Manchester, and between 2014-16 was Scientific Director of the International Centre for Mathematical Sciences (ICMS) in Edinburgh. 